\title{
Contemporary perspectives on effort: A special issue
}

\author{
Michael Richter $\cdot$ Rex A. Wright
}

Published online: 27 September 2014

(c) Springer Science+Business Media New York 2014

Motivation science is concerned with processes that govern behavior, specifically those that determine its initiation, direction, intensity, and persistence. Among the processes addressed by motivation theorists are ones related to effort. In psychology, discussions of effort trace back at least to Ach (1910, 1935) and Hillgruber (1912), who considered the role of "will" in overcoming performance barriers (see Heckhausen and Heckhausen 2010; Kuhl and Beckmann 1985). Discussions declined during the mid-portion of the past century when dominant motivation theories denied or ignored human executive function (Gollwitzer and Oettingen 2001; Graham and Weiner 1996). However, they rebounded as the century progressed, driven by emerging literatures that assumed at least an illusion of personal control. Interest in effort processes continued into the millennium and has remained high since, especially among investigators grappling with issues related to achievement, goal striving, and self-regulation. One indication of the current level of interest is the frequency with which the word "effort" has been referenced in psychology articles over the past decade. A search of the PsycINFO database produced 2,239 title references and 62,583 references in abstracts.

Given the history of effort discussions and the current level of interest in effort processes, one might think there would be a consensus on the character of the effort

\footnotetext{
M. Richter ( $\square)$

Geneva Motivation Lab, Department of Psychology, University of Geneva, 1205 Geneva, Switzerland

e-mail: Michael.Richter@unige.ch

R. A. Wright

Department of Psychology, University of North Texas, 1155

Union Circle \#311280, Denton, TX 76203-5017, USA

e-mail: Rex.Wright@unt.edu
}

construct. Unfortunately, this is not the case. Theorists and investigators tend to concur that effort pertains to the intensity of behavior (Brehm and Self 1989; Higgins 2006; Kahneman 1973; Kruglanski et al. 2012). However, they have divergent views regarding its fundamental essence as well as key questions relevant to volition and phenomenology (Gollwitzer 1996; Locke 1996; Wegner 2002). Theorists and investigators also have divergent views regarding the function of effort, with a growing number assuming an energy mobilization function (Gendolla and Wright 2009), but notable others taking contrary stances (e.g., Kurzban et al. 2013). Although disagreements about effort character are understandable and healthy in some respects, they impede the advancement of related science and must ultimately be resolved.

This special issue of Motivation and Emotion showcases work from eleven ongoing research programs concerned in some respect with effort. We organized it to raise awareness of the character and quality of contemporary effort research, emphasizing that the featured work is only representative of the larger body of effort work that is available. In raising awareness, we hoped to inspire further reflection on effort processes and to encourage non-effort investigators to consider implications of new effort conceptions and discoveries for their own research. We also hoped to facilitate relevant idea exchange-improving communication and the chance for emergent insights, including ones relevant to effort construct debates. Readers will see that the featured work addresses a rich array of effort issues, with themes ranging from priming influence to effort effects on goal value. Themes allowed for different possible organizational schemes; thus, we decided somewhat arbitrarily to structure in four sections. Articles in Section 1 involve the priming theme, specifically, addressing the role priming plays in determining effort outcomes. 
Lasauskaite Schüpbach et al. (in press) begin by presenting research concerned with facial primes expressing different emotions. Findings indicate that cardiovascular responses to more and less difficult behavioral challenges can be influenced by such primes with the character of cardiovascular effects depending on the emotion expressed and the duration of prime presentations. The authors suggest that results reflect control processes that moderate the impact of facial expressions on effort if the stimuli are fully processed. Pas et al. (in press) complete the section discussing research concerned with the duration of reward primes and neural mechanisms that mediate their effort influence. Central findings were twofold. First, both suboptimal (extremely brief) and optimal (more extended) reward primes increased indices of effort. Second, this reward effect was correlated with markers of striatal dopaminergic activity (resting state eye-blink rate and error-related negativity) only if primes were presented suboptimally. Pas and colleagues conclude that different neuronal mechanisms underlie the effect of primes presented for different durations.

Our second section includes three articles that address further-and in different ways- the link between rewards and effort. The first, by Marien et al. (in press), considers the question of whether reward cues invariably lead to high effort. It presents response time evidence suggesting that such cues improve effort if task requirements high, but not if they are low. The remaining articles consider the impact of depressive symptoms on effort mobilization, using selected cardiovascular measures to assess effort and drawing on the idea that depression leads to reduced reward sensitivity. Silvia et al. (in press) report a study that examined the link between depressive symptoms and sympathetic myocardial activity in regard to a parity task, with findings indicating an inverse relation between effort investment and the number of depressive symptoms. Brinkmann et al. (in press) report research that presented dysphoric and non-dysphoric participants a memory task that did or did not allow them to earn social approval. Whereas non-dysphoric participants responded to the social approval incentive with increased effort, dysphoric participants did not.

Section 3 consists of four articles concerned with appraisals - of the self, of instrumental task demand, of goal value, and of effort itself. Bélanger et al. (in press) consider the role cognitive resources play in determining motive congruent judgments pertaining to the self. Following theoretical arguments advanced by Kruglanski et al. (2012), they predicted and found that effortful biasing occurs only if sufficient resources are available. Building on other perception research, Cole et al. (in press) consider how attention focus might affect judgments of how hard it will be to satisfy motives. In studies involving walking distance, they found that a narrow attention focus led to reduced difficulty judgments and-additionally-faster walking speeds. Regarding appraisals of goal value, Sehert et al. (in press) present research that examined the impact of effort investment on the value of objects that might be acquired or avoided. Results comported with their argument that outcome scarcity intensifies attention which, in turn, intensifies outcome valence. Objects with a positive default value were rated as more valuable if they were scarce, whereas objects with a negative default value were rated as less so. Sehert and colleagues also provide evidence that the preceding attention effect is not limited to the scarce object, but rather may transfer to other, unrelated ones. Robinson and Morsella (in press) conclude the section presenting research that investigated feelings of effort associated with cognitive tasks requiring attention, assessment, and choice. Attention tasks were rated as more effortful than choice tasks, with assessment tasks falling in between.

Articles in our fourth section close the special issue powerfully with outstanding discussions pertaining to age and action deterrent influence on effort. Hess and Ennis (in press) present an age analysis and literature review, noting difficulties with traditional effort measures. Drawing on research that has employed cardiovascular measures to test effort hypotheses-such as some of that which is presented here (e.g., Brinkmann et al. in press; Silvia et al. in press) - they elaborate on the potential utility of systolic blood pressure as an effort index. Pantaleo et al. (in press) draw from Brehm's emotion intensity idea's (Brehm 1999; Miron and Brehm 2012) to make predictions about effects of deterrence in a group context. As expected, they found that moderate group deterrents yielded higher engagement in group goal-related activities and higher group identification than weak or very strong group deterrents.

We are proud of this collection of articles. It does not represent the full body of effort research being conducted, but it does convey a fair flavor of the work that is available. The featured work is diverse and fundamentally basic, although with implications for behavior in real world settings. As intimated earlier in our comments on the effort construct, diversity can be viewed as both a blessing and a curse from the perspective of scientific advancement. It is a blessing insofar as it promotes inventive and integrative thinking. On the other hand, it is a curse insofar as it interferes with communication and collaboration. We suspect that mixed consequences have followed from the present heterogeneity in effort perspectives and would be pleased if this special issue improved in any measure the favorability of the consequence balance.

Acknowledgments We are grateful to numerous colleagues for providing thoughtful manuscript reviews and would like to thank 
publically Henk Aarts, Tobias Brosch, Ruud Custers, Stephen Fairclough, Kerstin Fröber, Guido H. E. Gendolla, Cedar R. Riener, Katharina Schnitzspahn, Paul Silvia, Jeanine K. Stefanucci, Michael Treadway, and Athina Zafeiriou.

\section{References}

Ach, N. (1910). Über den Willensakt und das Temperament [On the will and temperament]. Leipzig, Germany: Quelle und Meyer.

Ach, N. (1935). Analyse des Willens [Analysis of the will]. Berlin, Germany: Urban Schwarzenberg.

Bélanger, J. J., Kruglanski, A. W., Chen, X., \& Orehek, E. (2014). Bending perception to desire: Effects of task demands, motivation, and cognitive resources. Motivation and Emotion. doi:10. 1007/s11031-014-9436-z.

Brehm, J. W. (1999). The intensity of emotion. Personality and Social Psychology Review, 3, 2-22. doi:10.1207/s15327957pspr0301_1.

Brehm, J. W., \& Self, E. A. (1989). The intensity of motivation. Annual Review of Psychology, 40, 109-131.

Brinkmann, K., Franzen, J., Rossier, C., \& Gendolla, G. H. E. (2014). I don't care about others' approval: Dysphoric individuals show reduced effort mobilization for obtaining a social reward. Motivation and Emotion. doi:10.1007/s11031-014-9437-y.

Cole, S., Riccio, M., \& Balcetis, E. (2014). Focused and fired up: Narrowed attention produces proximity and increases goalrelevant action. Motivation and Emotion. doi:10.1007/s11031014-9432-3.

Gendolla, G. H. E., \& Wright, R. A. (2009). Effort. In D. Sander \& K. R. Scherer (Eds.), Oxford companion to the affective sciences (pp. 134-135). New York, NY: Oxford University Press.

Gollwitzer, P. M. (1996). The volitional benefits of planning. In P. M. Gollwitzer \& J. S. Bargh (Eds.), The psychology of action: Linking cognition and motivation to behavior (pp. 287-312). New York, NY: Guilford.

Gollwitzer, P. M., \& Oettingen, G. (2001). Motivation: History of the concept. In N. J. Smelser \& P. B. Baltes (Eds.), International encyclopedia of the social and behavioral sciences (pp. 10109-10112). New York, NY: Elsevier.

Graham, S., \& Weiner, B. (1996). Theories and principles of motivation. In D. C. Berliner \& R. C. Calfee (Eds.), Handbook of educational psychology (pp. 63-84). New York, NY: Simon \& Schuster Macmillan.

Heckhausen, J., \& Heckhausen, H. (2010). Motivation and action (2nd ed.). New York, NY: Cambridge University Press.

Hess, T. M., \& Ennis, G. E. (2014). Assessment of adult age differences in task engagement: The utility of systolic blood pressure. Motivation and Emotion. doi:10.1007/s11031-014-9433-2.

Higgins, E. T. (2006). Value from hedonic experience and engagement. Psychological Review, 113, 439-460.
Hillgruber, A. (1912). Fortlaufende Arbeit und Willensbetätigung [Continuous work and the will]. Leipzig, Germany: Quelle und Meyer.

Kahneman, D. (1973). Attention and effort. Englewood Cliffs, NJ: Prentice-Hall.

Kruglanski, A. W., Bèlanger, J. J., Chen, X., Köpetz, C., Pierro, A., \& Mannetti, L. (2012). The energetics of motivated cognition: A force-field analysis. Psychological Review, 119, 1-20.

Kuhl, J., \& Beckmann, J. (1985). Action control: From cognition to behavior. Berlin: Springer.

Kurzban, R., Duckworth, A. L., Kable, J. W., \& Myers, J. (2013). An opportunity cost model of subjective effort and task performance. Behavioral and Brain Sciences, 36, 661-679.

Lasauskaite Schüpbach, R., Gendolla, G. H. E., \& Silvestrini, N. (2014). Contrasting the effects of suboptimally versus optimally presented affect primes. Motivation and Emotion. doi:10.1007/ s11031-014-9438-x.

Locke, E. A. (1996). Motivation through conscious goal setting. Applied and Preventive Psychology, 5, 117-124.

Marien, H., Aarts, H., \& Custers, C. (2014). Reward-driven modulation of adaptive control: How prospective monetary gains interact with unpredictable control demands. Motivation and Emotion. doi:10.1007/s11031-014-9439-9.

Miron, A. M., \& Brehm, J. W. (2012). Emotional intensity theory and its cardiovascular implications for emotional states. In $\mathrm{R}$. A. Wright \& G. H. E. Gendolla (Eds.), How motivation affects cardiovascular response: Mechanisms and applications (pp. 121-137). Washington, DC: American Psychological Association.

Pantaleo, G., Miron, A. M., Ferguson, M. A., \& Frankowski, S. D. (2014). Effects of deterrence on intensity of group identification and efforts to protect group identify. Motivation and Emotion. doi:10.1007/s11031-014-9440-3.

Pas, P., Custers, R., Bijleveld, E., \& Vink, M. (2014). Effort responses to suboptimal reward cues are related to striatal dopaminergic functioning. Motivation and Emotion. doi:10.1007/s11031-0149434-1.

Robinson, M. M., \& Morsella, E. (2014). The subjective effort of everyday mental tasks: Attending, assessing, and choosing. Motivation and Emotion. doi:10.1007/s11031-014-9441-2.

Sehnert, S., Franks, B., Yap, A. J., \& Higgins, E. T. (2014). Scarcity, engagement, and value. Motivation and Emotion. doi:10.1007/ s11031-014-9442-1.

Silvia, P. J., Nusbaum, E. C., Eddington, K. M., Beaty, R. E., \& Kwapil, T. R. (2014). Effort deficits and depression: The influence of anhedonic depressive symptoms on cardiac autonomic activity during a mental challenge. Motivation and Emotion. doi:10.1007/s11031-014-9443-0.

Wegner, D. M. (2002). The illusion of conscious will. Cambridge, MA: MIT Press. 